\title{
Is serum procalcitonin level a reliable indicator in early diagnosis of congenital pneumonia?
}

\author{
Davut Bozkaya, Şule Yiğit, Murat Yurdakök \\ Division of Neonatology, Department of Pediatrics, Hacettepe University Faculty of Medicine, Ankara, Ankara, Turkey. \\ E-mail: drbozkaya@gmail.com \\ Received: 4th July 2018, Revised: 9th September 2018, 22nd November 2018, Accepted: 29th \\ January 2019
}

SUMMARY: Bozkaya D, Yiğit Ş, Yurdakök M. Is serum procalcitonin level a reliable indicator in early diagnosis of congenital pneumonia? Turk J Pediatr 2019; 61: 34-39.

The clinical signs in congenital pneumonia mimic other conditions like transient tachypnea of the newborn (TTN) and respiratory distress syndrome (RDS). Differential diagnosis is difficult since laboratory findings have limited value. Procalcitonin (PCT) is an important and widely studied marker of infection. The aim of this study was to determine the diagnostic value of PCT in newborn patients hospitalized in the neonatal intensive care unit (NICU) with the diagnosis of congenital pneumonia.

The infants with respiratory distress who were born at Hacettepe University between 2005-2015 and hospitalized in the NICU were included in the study.

A total of 200 newborn infants; 54 (27\%) infants with congenital pneumonia (Group-1), 42 (21\%) infants with TTN (Group-2), 40 (20\%) infants with RDS (Group-3) and $64(32 \%)$ healthy infants (group-4), were included in the study. There was no statistically significant difference between the groups for serum C-reactive protein (CRP) levels, sampling time for PCT and CRP and the characteristics of the mother $(p>0.05)$. Mean serum PCT level was higher in the congenital pneumonia group than in the other groups $(\mathrm{p}<0.001)$.

Result of this study shows that procalcitonin is an important early marker in the diagnosis of congenital pneumonia.

Key words: newborn, congenital pneumonia, procalcitonin.

During the neonatal period, pneumonia can be classified as early-onset and late- onset pneumonia. Early onset pneumonia is described as the presentation of clinical findings of pneumonia in the first week of life. Congenital pneumonia is defined as neonatal pneumonia associated with prolonged premature rupture of membranes, maternal infections, chorioamnionitis and perinatal infections. Congenital pneumonia can be accepted as a subgroup of early onset pneumonia and clinical findings usually appear within first day of life. ${ }^{1,2}$

Neonatal autopsy studies have shown that intrauterine and early-onset pneumonia occurs in $10-38 \%$ of stillborn and $20-63 \%$ of live born babies who subsequently died. The cause of death in the first 48 hours of life found was found to be pneumonia in $20-38 \%$ of cases, with the highest incidence in lower socioeconomic groups. ${ }^{1,3,4}$

Congenital pneumonia is a severe disease that sometimes progress to septic shock and can be associated with persistent pulmonary hypertension. Early diagnosis and treatment of congenital pneumonia is very important to prevent mortality and morbidities. The clinical signs of congenital pneumonia may mimic other conditions like transient tachypnea of the newborn (TTN) and respiratory distress syndrome (RDS) thus, making it difficult to distinguish between them since laboratory findings are usually not helpful. If pneumonia is suspected, initial screening tests, including complete blood count and blood culture, should be obtained before beginning antibiotic therapy. Congenital pneumonia occurs in the setting 
of a maternal systemic infection, which may or may not be symptomatic in the mother. ${ }^{5,6}$ Conventional bacteriological culture is the most widely used and the most helpful test. However, it was reported that a number of factors may interfere with the ability to cultivate a likely pathogen from the sites. ${ }^{1}$ Pretreatment with antibiotics limit in vitro but not in vivo growth, contaminants that overgrow the pathogen and pathogens that do not replicate in currently available culture systems. The use of markers of inflammation to support the diagnosis of pneumonia, remains controversial. It has been concluded that decisions about antimicrobial therapy should not be based on inflammatory markers alone such as C-reactive protein (CRP), cytokines (e.g. IL-6), and other acute phase reactants. ${ }^{1}$ Procalcitonin (PCT) is one of the inflammatory markers. It has been reported that PCT is useful in identifying bacteraemia among children with pneumonia. ${ }^{8}$

PCT, a calcitonin precursor peptide, has been one of the most studied markers in newborns. However, there is no study showing the sensitivity, specificity or the negative or positive predictive values of the PCT in congenital pneumonia. ${ }^{7,9}$

The aim of this study was to determine the diagnostic value of PCT in newborns hospitalized in the neonatal intensive care unit (NICU) with the diagnosis of congenital pneumonia.

\section{Material and Methods}

This retrospective study was conducted at Hacettepe University Neonatal Intensive Care Unit. Infants who were born between January 2005 and August 2015 with respiratory distress (respiratory rate $>60 / \mathrm{min}$, nasal flaring, intercostal and / or jugular retraction, oxygen need) in the first 72 hours of life were included in the study. The research procedure was approved by the local ethical committe (IRB Number: GO 16/175). Demographic characteristics, laboratory results, final diagnosis of infants and maternal history (prolonged premature rupture of membranes longer than $>24$ hours, maternal genitourinary infection, chorioamnionitis and antibiotic use) were obtained from records. All chest $\mathrm{x}$-rays were reevaluated with radiology specialists. Congenital pneumonia was determined according to clinical, chest $\mathrm{x}$-rays and CRP values. Infants with major congenital malformations and chromosomal anomalies were excluded from study. Maternal diabetes mellitus, and connective tissue disorders also are excepted as exclusion criteria.

The control group consisted of healthy patients who were screened due to maternal history at the same period. Patients were divided into four groups as follows

Group -1: The patients were diagnosed with pneumonia using chest $\mathrm{x}$ ray, laboratory and clinical findings.

Group-2: The infants diagnosed with transient tachypnea of the newborn (TTN).

Group -3: The infants diagnosed with respiratory distress syndrome (RDS), and whom received surfactant

Group 4- Healthy infants, whose birth week and sampling time were similar to the study groups.

The demographic characteristics and sampling time of groups 2, and 4 were similar to group-1. Group 3 consisted of patients with RDS and, as expected their gestational ages and birth weights were different from other groups however sampling time was similar.

Serum PCT and CRP levels at between the 2nd and 72nd hours of age were measured. The measurement of CRP levels was made using the latex nephelometry method (BeckmanCoulter ABD). PCT was measured by a specific "fluorimetric immunoassay" method (Kryptor; Brahms, Hennigsdorf, Germany.

\section{Statistical analysis}

SPSS for windows 17.0 version was used for statistical analysis. Non parametric tests were used because the data were not normally distributed. Results were compared by the Mann Whitney U test. Sensitivity, specificity, positive predictive value (PPV) and the negative predictive value (NPV) of PCT were determined. The PCT cut-off value was attained from receiver-operating characteristic curve (ROC). All statistical analysis was performed by SPSS 23 (SPSS Inc., Chicago, IL, USA.).

\section{Results}

A total of 200 newborn infants; 54 (21\%) infants with congenital pneumonia (Group-1), 
Table I. Demographic Characteristics and Laboratory Results of The All Groups.

\begin{tabular}{|c|c|c|c|c|c|}
\hline Variables & $\begin{array}{l}\text { Group-1 (n:54) } \\
\text { Median (IQR) }\end{array}$ & $\begin{array}{l}\text { Group-2 (n:42) } \\
\text { Median (IQR) }\end{array}$ & $\begin{array}{l}\text { Group-3 (n:40) } \\
\text { Median (IQR) }\end{array}$ & $\begin{array}{l}\text { Group-4(n:64) } \\
\text { Median (IQR) }\end{array}$ & $\mathrm{P}$ value* \\
\hline $\begin{array}{l}\text { Gestational age } \\
\text { (week) }\end{array}$ & $\begin{array}{c}37 \pm 2 \\
(31.1-40.7)\end{array}$ & $\begin{array}{c}37 \pm 2 \\
(30.4-40.6)\end{array}$ & $\begin{array}{c}34 \pm 3^{*} \\
(26.5-39.6)\end{array}$ & $\begin{array}{c}38 \pm 2 \\
(34.0-41.0)\end{array}$ & 0.000 \\
\hline Birth weight (g) & $\begin{array}{l}2885 \pm 540 \\
(1600-4450)\end{array}$ & $\begin{array}{l}2936 \pm 547 \\
(1400-3780)\end{array}$ & $\begin{array}{c}2157 \pm 822^{*} \\
(620-4400)\end{array}$ & $\begin{array}{l}3012 \pm 495 \\
(1870-3940)\end{array}$ & 0.000 \\
\hline $\operatorname{Sex}(M / F)$ & $20 / 34$ & $20 / 22$ & $15 / 25$ & $34 / 30$ & 0.3 \\
\hline $\begin{array}{l}\text { Sampling time } \\
\text { (postnatal hour) }\end{array}$ & $\begin{array}{c}11 \pm 8 \\
(1-31)\end{array}$ & $\begin{array}{c}21 \pm 28 \\
(6-144)\end{array}$ & $\begin{array}{l}7 \pm 6 \\
(2-24)\end{array}$ & $\begin{array}{c}12 \pm 2 \\
(1-37)\end{array}$ & 0.70 \\
\hline PCT (ng/dl) & $\begin{array}{c}7.56 * \\
(1.86-15.53)\end{array}$ & $\begin{array}{c}0.52 \\
(0.24-2.63)\end{array}$ & $\begin{array}{c}0.24 \\
(0.12-0.77)\end{array}$ & $\begin{array}{c}0.79 \\
(0.18-2.30)\end{array}$ & 0.001 \\
\hline CRP (mg/dl) & $\begin{array}{c}0.24 \\
(0.12-0.30)\end{array}$ & $\begin{array}{c}0.10 \\
(0.24-0.12)\end{array}$ & $\begin{array}{c}0.10 \\
(0.25-0.19)\end{array}$ & $\begin{array}{c}0.19 \\
(0.11-0.28)\end{array}$ & 0.053 \\
\hline $\mathrm{WBC}\left(10^{3} / \mathrm{uL}\right)$ & $\begin{array}{c}16700 \\
(13000-20000)\end{array}$ & $\begin{array}{c}18050 \\
(12300-22800)\end{array}$ & $\begin{array}{c}15700 \\
(12500-20300)\end{array}$ & $\begin{array}{c}17400 \\
(14900-21600)\end{array}$ & 0.53 \\
\hline
\end{tabular}

M/F: male/female, PCT, Procalcitonin; CRP, C-reactive protein, WBC: White Blood Cells

*: One-Way ANOVA/Post hoc test (test $\mathrm{p}<0.05$ significant)

$42(21 \%)$ infants with TTN (Group-2), 40 (20\%) infants with RDS (Group-3) and 64(32\%) healthy infants (group-4), were included in the study. The demographic characteristics of the groups and CRP, PCT values and sampling time are summarized in Table I. There were statistically significant differences for the gestational ages and birth weights between group-3 and other groups $(\mathrm{p}<0.05)$.

There was no statistical difference between the mean gestational ages, and mean birth weights of the groups 1, 2, 4. Sampling time were similar in all groups. Mean PCT levels was 7.56 (1.86 15.53) (Median (IQR)) in the group 1, 0.52 (0.24-2.63) (Median (IQR)) in the group 2, $0.24(0.12-0.77)$ (Median (IQR)) in the group 3 and $0.79(0.18-2.30)$ (Median (IQR)) in the group 4. When the serum PCT levels were evaluated in the four groups, there was statistically significant difference in PCT levels between group-1 and other groups $(\mathrm{p}<$ $0.005)$. However, there was no statistically significant difference between groups for the serum CRP levels, sampling time for PCT and CRP and the characteristics of the mother ( $p>$ 0.05). The optimal cut-off values of PCT and
CRP were estimated by ROC curves (Figs 1 and 2). For these cut-off values, AUC values were 0.81 for PCT (95\% CI; 0.76-0.89). At a cutoff of $1.55 \mathrm{ng} / \mathrm{ml}$, sensitivity of PCT was $66.7 \%$, specificity of PCT was $88.8 \%$, negative predictive value of PCT was $90 \%$, positive predictive value of PCT was $51 \%$ for congenital pneumonia in neonates. Predictive values of PCT and CRP levels are summarized in Table II. Box Graphs of Distribution of PCT is given in Figure 3.

\section{Discussion}

In this study, we found that serum PCT levels were significantly higher in the respiratory disorders group than in the control group.

Procalcitonin, a precursor of calcitonin, is a glycoprotein which is normally synthesized by thyroid gland C-cells and plays a role in calcium homeostasis. Systemic inflammation can trigger extrathyroidal non-neuroendocrine calcitonin gene expression. Procalcitonin begins to rise within 3-4 hours in response to bacterial endotoxins and reaches its maximum value after 6-8 hours. The half-life is about 24 hours. ${ }^{11,12}$ Because of this rapid response to 
Table II. Predictive Values and of Procalcitonin Level (PCT) and CRP Level for the Diagnosis of Congenital Pneumonia.

\begin{tabular}{lccccc}
\hline Variables & $\begin{array}{c}\text { Cutoff value } \\
(\%)\end{array}$ & $\begin{array}{c}\text { Sensitivity } \\
(\%)\end{array}$ & $\begin{array}{c}\text { Specificity } \\
(\%)\end{array}$ & $\begin{array}{c}\text { PPV } \\
(\%)\end{array}$ & $\begin{array}{c}\text { NPV } \\
(\%)\end{array}$ \\
\hline PCT $(\mathrm{ng} / \mathrm{dl})$ & 1.55 & 66.7 & 88.8 & 51 & 90 \\
CRP $(\mathrm{mg} / \mathrm{dl})$ & 1.01 & $\% 26,2$ & $\% 75,3$ & 13 & 75 \\
\hline
\end{tabular}

PPV: positive predictive value, NPV: negative predictive value, PT: power of the test

bacterial endotoxins, PCT has been defined as an early marker of infections since the late nineties. ${ }^{13}$ However PCT has not been accepted as a diagnostic marker of infection in neonatal patients until recent years due to contradictory reports in literature. Falsely increased PCT concentrations have been reported in critically ill newborns with noninfectious etiology, these reports were criticized due to the heterogeneity of study groups, such as wide ranging differences in gestational ages, birth weights and postnatal ages. ${ }^{14}$ It was reported that these studies and their conclusion should be interpreted with caution . ${ }^{11}$ Frendler et al. ${ }^{15}$ showed that PCT was valuable for early detection of nosocomial sepsis in newborn infants and the highest levels of PCT have been determined in gram negative infections. In another study, Lencot $\mathrm{S}$ et al. ${ }^{10}$ used cord

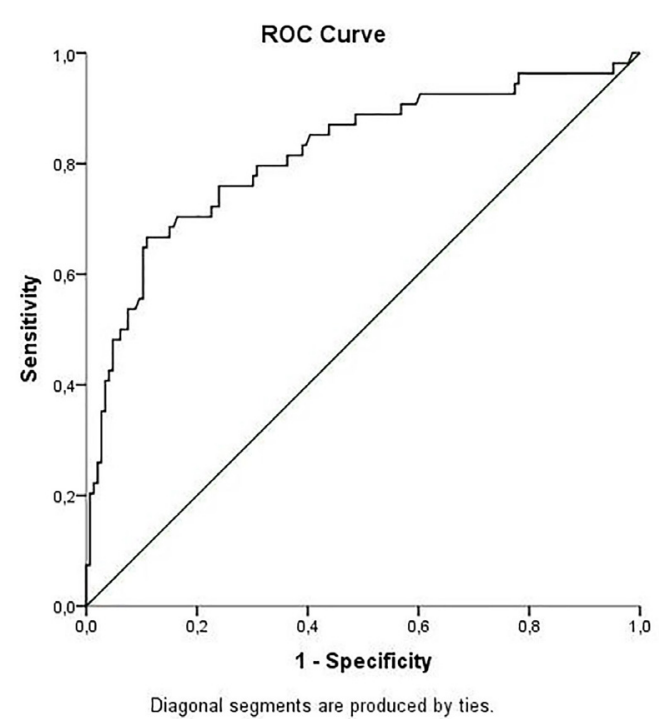

Fig. 1. Comparison of The Receiver Operating Characteristic (ROC) Curves of Procalcitonin (PCT). The area under the curve was 0.84 for PCT. The difference between areas was significant (95\% confidence interval, CI; 0.74-0.89) $(\mathrm{p}=0.001)$ blood PCT levels to distinguish infected infants from healthy ones with a cut-off value of 0.6 $\mathrm{ng} / \mathrm{ml}$. Infants, cord blood PCT levels higher than $0.6 \mathrm{ng} / \mathrm{ml}$, underwent diagnostic tests for evaluating early onset neonatal infection. They reported that this algorithm significantly reduced blood samples and antibiotic treatment. Kocabas et al. ${ }^{16}$ concluded that PCT and TNF- $\alpha$ were the best markers in the diagnosis of neonatal sepsis.

In our clinic, PCT level has been used in making the decision to start treatment in early neonatal infection for nearly 10 years. A previously published study performed in our clinic showed that PCT was a reliable marker of early onset infection in neonatal patients. ${ }^{17}$

Although PCT has been used in making a decision to start antibiotics, it has not been

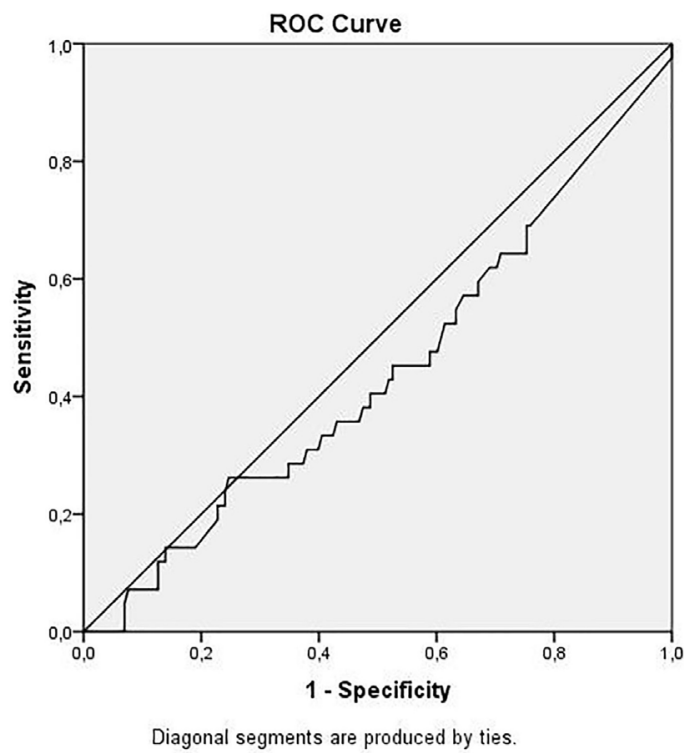

Fig. 2. Comparison of The Receiver Operating Characteristic (ROC) Curves of CRP. The area under the curve was 0.44 for CRP. The difference between areas was significant $(95 \%$ confidence interval, CI; 0.34-0.54) $(p=0.239)$ 


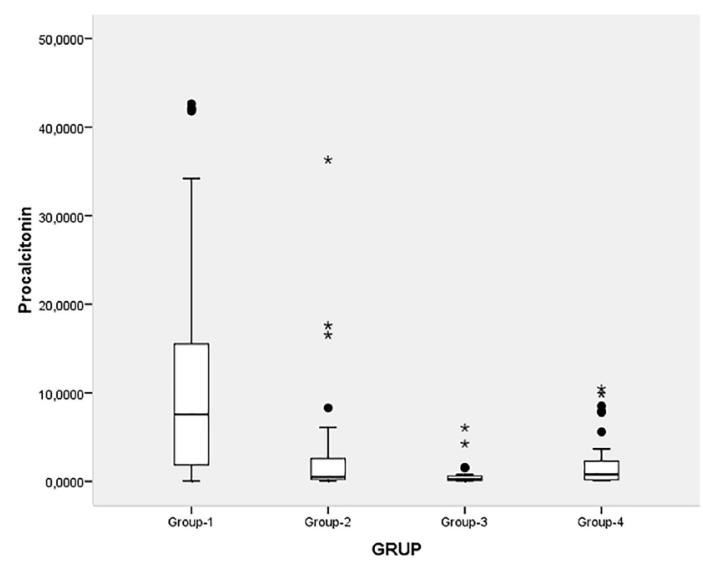

Fig. 3. Box Graphs of Distribution of Procalcitonin Levels in All Groups

used to terminate treatment. During this period it was noticed that high levels of PCT were found in patients with respiratory distress, mainly in congenital pneumonia. It was reported that PCT is useful in identifying bacteraemia among children with pneumonia. ${ }^{18}$ In the study a group of newborn patients with respiratory disorder (transient tachypnea of the newborn, respiratory distress syndrome, air leak syndrome, meconium aspiration syndrome, 18-trisomy, severe neonatal asphyxia and congenital diaphragmatic hernia) was compared to newborns without any respiratory disorder (control group). Serum PCT was found to be significantly higher in the respiratory disorders group when compared to the control group. However, none of the cases in the respiratory disorders group had an active infection. Whereas, in our study we did not find any statistically significant difference between CRP and WBC levels in all groups. At the same time, PCT values were not statistically significant when compared to timing of blood sampling for PCT. Similar to their study mean sampling time was within 24 hours in our study. In contrast to their study we did not find increase in PCT levels in infants with TTN or RDS. Our study shows ability of procatitonin to differentiate bacterial pulmonary infections from other respiratory morbidities.

In previous studies, the sensitivity of PCT was calculated as \%83-100 and the specificity \%70-100. ${ }^{19}$ In this study we determined the sensitivity of PCT to be $66.7 \%$ and its specificity was $88.8 \%$, positive predictive value and negative predictive value were $51 \%$ and $90 \%$, respectively, and the power of the test was $71.9 \%$. High specificity and high negative predictive value of PCT determined in this study indicate that PCT is a good marker in congenital pneumonia.

Our study shows that in newborns with congenital pneumonia PCT can be used for early diagnosis together with clinical findings. This will in turn decrease the mortality and morbidity due to congenital pneumonia. Additionally, newborns receiving RDS diagnoses may be spared from receiving prophylactic antibiotic treatment after surfactant therapy. In conclusion, this is the first study shows that procalcitonin is an important early marker in the diagnosis congenital pneumonia.

\section{REFERENCES}

1. Nissen MD. Congenital and neonatal pneumonia. Paediatr Respir Rev 2007; 8: 195-203.

2. Duke T. Neonatal pneumonia in developing countries. Arch Dis Child Fetal Neonatal Ed 2005; 90: F211-F219.

3. Barton L, Hodgman JE, Pavlova Z. Causes of death in the extremely low birth weight infant. Pediatrics 1999; 103: 446-451.

4. Feria-Kaiser C, Furuya ME, Vargas MH, Rodriguez A, Cantu MA; Mortality Committee. Main diagnosis and cause of death in a neonatal intensive care unit: Do clinicians and pathologists agree? Acta Paediatr 2002; 91: 453-458.

5. Walsh WF. Neonatal pneumonia. Semin Pediatr Infect Dis 1995; 6: 166-173.

6. Davies PA, Aherne W. Congenital pneumonia. Arch Dis Child 1962; 37: 598-602.

7. Delanghe JR, Speeckaert MM. Translational research and biomarkers in neonatal sepsis. Clin Chim Acta 2015; 451(Pt A): 46-64.

8. Machado JR, Soave DF, da Silva MV, et al. Neonatal sepsis and inflammatory mediators. Mediators Inflamm 2014; 2014: 269681.

9. Park IH, Lee SH, Yu ST, Oh YK. Serum procalcitonin as a diagnostic marker of neonatal sepsis. Korean J Pediatr 2014; 57: 451-456.

10. Lencot S, Cabaret B, Sauvage G, et al. A new procalcitonin cord-based algorithm in early-onset neonatal infection: For a change of paradigm. Eur J Clin Microbiol Infect Dis 2014; 33: 1229-1238.

11. Chiesa C, Pacifico L, Osborn JF, Bonci E, Hofer N, Resch B. Early-onset neonatal sepsis: Still room for improvement in procalcitonin diagnostic accuracy studies. Medicine (Baltimore) 2015; 94: e1230.

12. van Rossum AM, Wulkan RW, Oudesluys-Murphy AM. Procalcitonin as an early marker of infection in neonates and children. Lancet Infect Dis 2004; 4: 620-630. 
13. Chiesa C, Pacifico L, Mancuso G, Panero A. Procalcitonin in pediatrics: Overview and challenge. Infection 1998; 26: 236-241.

14. Bonac B, Derganc M, Wraber B, Hojker S. Interleukin-8 and procalcitonin in early diagnosis of early severe bacterial infection in critically ill neonates. Pflugers Arch Eur J Physiol 2000(Suppl 5); 440: R72-R74.

15. Fendler WM, Piotrowski AJ. Procalcitonin in the early diagnosis of nosocomial sepsis in preterm neonates. $\mathrm{J}$ Paediatr Child Health 2008; 44: 114-118.

16. Kocabas E, Sarikcioglu A, Aksaray N, Seydaoglu G, Seyhun Y, Yaman A. Role of procalcitonin, C-reactive protein, interleukin-6, interleukin-8 and tumor necrosis factor-alpha in the diagnosis of neonatal sepsis. Turk J Pediatr 2007; 49: 7-20.
17. Canpolat FE, Yigit S, Korkmaz A, Yurdakok M, Tekinalp G. Procalcitonin versus CRP as an early indicator of fetal infection in preterm premature rupture of membranes. Turk J Pediatr 2011; 53: 180-186.

18. Ochi F, Higaki T, Ohta M, et al. Procalcitonin as a marker of respiratory disorder in neonates. Pediatr Int 2015; 57: 263-268.

19. Simon L, Gauvin F, Amre DK, Saint-Louis P, Lacroix J. Serum procalcitonin and C-reactive protein levels as markers of bacterial infection: A systematic review and meta-analysis. Clin Infect Dis 2004; 39: 206-217. 